\title{
THE ROLE OF SMALL BUSINESS IN ECONOMIC DEVELOPMENT OF EUROPEAN ECONOMY
}

\author{
Ştefania Anca Stan \\ „Vasile Alecsandri” University of Bacau \\ anca_stan68@yahoo.com
}

\begin{abstract}
Small businesses provide catalytic benefits to the economy. They contribute to national output, and to the society as a whole, beyond the spending and profit they generate. The role of SMEs is crucial for the European economic recovery - their number, employment capacity and value added constitute a large share of the European economy. Providing the right conditions in which SMEs can flourish is paramount for ensuring a sustained recovery and achieving prosperity for all EU citizens. There is no single agreed definition of an SME. Early definitions of 'small' businesses were largely qualitative. SMEs are generally considered to be non subsidiary, independent firms which employ fewer than a given number of employees. For many small businesses, going global is no longer just an interesting to do - it is essential to the long - term health and performance of the company. Across the EU policies are being developed at regional, national and transnational government level that see SMEs as the only positive way of creating employment and generating increased local growth for the community.
\end{abstract}

\section{Keywords}

small and medium enterprises; innovation; entrepreneurship; economic development; globalization

\section{JEL Classification}

M10

\section{Introduction}

Small businesses provide catalytic benefits to the economy. They contribute to national output, and to the society as a whole, beyond the spending and profit they generate.

Small business demonstrated its durability during the 1970s and 1980s in particular. At the time, foreign competition led to a decline of basic, large-scale manufacturing companies in such industries as steel, automobiles, and textiles. In the new global economy, services became relatively more important while manufacturing became less important, and that meant a growing role for small companies, which traditionally have dominated many service sectors.

But some economists saw additional reasons why small business would become a more important part of the economic landscape. In the highly competitive and rapidly changing global economy, they argued, companies that could innovate, customize products, and adapt quickly to changing circumstances would have an edge. Small business, with less hierarchical management systems and less unionized workforces, seemed to have just these strengths. What is more, small businesses got an extra boost because declining transportation costs and the emergence of the Internet made it easier than ever for them to compete on the global stage. 


\section{Defining the SME}

There is no single agreed definition of an SME. Early definitions of 'small' businesses were largely qualitative. SMEs are generally considered to be non subsidiary, independent firms which employ less than a given number of employees. This number varies across countries. The most frequent upper limit designating an SME is 250 employees, as in the European Union. However, some countries set the limit at 200, while the United States considered SMEs to include firms with fewer than 500 employees. Small firms are mostly considered to be firms with fewer than 50 employees while micro-enterprises have at most ten, or in some cases, five employees.

Financial assets are also used to define SMEs. In the European Union, a new definition came into force on 1 January 2005 applying to all Community acts and funding programmers as well as in the field of State aid where SMEs can be granted higher intensity of national and regional aid than large companies. The new definition provides for an increase in the financial ceilings: the turnover of medium - sized enterprises (50-249 employees) should not exceed EUR 50 million: that of small enterprises (10-49 employees) should not exceed EUR 10 million while that of micro firms ( less than 10 employees) should not exceed EUR 2 million.

Alternatively, balance sheets for medium, small and micro enterprises should not exceed EUR 43 million, EUR 10 million and EUR 2 million, respectively.

Table 1 EU Definition of SMEs

\begin{tabular}{|c|c|c|c|}
\hline $\begin{array}{c}\text { Company } \\
\text { Category }\end{array}$ & Employees & Turnover & Balance sheet total \\
\hline Micro & $<10$ & $<2$ million EURO & $<2$ million EURO \\
\hline Small & $<50$ & $<10$ million EURO & $<10$ million EURO \\
\hline Medium - sized & $<250$ & $<50$ million EURO & $<43$ million EURO \\
\hline
\end{tabular}

In addition to satisfying the criteria for the number of staff and one of the two financial thresholds, an SME must be independent: to this end, the new definition distinguishes between autonomous enterprises, partner enterprises and linked enterprises. Finally, the new definition, introducing precise financial thresholds for micro- enterprises, thus recognizes the essential role of the latter in the economy.

Small businesses are frequently dominated and controlled by one person. The entrepreneur or owner-manager has an overwhelming influence on all aspects of the firm's direction, development and performance. This can be both strength and a weakness. Business decisions are often personal decisions and the logic of the balance sheet and rational economic criteria may not always apply.

Most firms begin small and remain small throughout their life cycle. A very small percentage grows to moderate size. A smaller minority grows to be large and even fewer become giant firms. These are the so-called gazelles whose contributions to employment and growth constitute modern legends.

Changes in technology, markets, and values will encourage the evolution of new types of firms.

\section{The SME business environment in Europe}

The 20 million European SMEs play an important role in the European economy. These are mostly micro-enterprises and in 2012 employed approximately 86.8 million people. This represents $66.5 \%$ of all European jobs for that year. Micro-enterprises provide just under a third of that total employment figure. The SME sector as a whole 
delivered $57.6 \%$ of the gross value added generated by the private, non-financial economy in Europe during 2012.

Table 2 Enterprises, Employment and Gross Value Added of SMEs in the $\mathrm{EU}-27,2012$

\begin{tabular}{|c|c|c|c|c|c|c|}
\hline Criteria & Micro & Small & $\begin{array}{l}\text { Medi } \\
\text { um }\end{array}$ & SMEs & Large & Total \\
\hline Number of & \multicolumn{6}{|l|}{ Enterprises } \\
\hline Number & 18.783 .480 & 1.349 .730 & $\begin{array}{r}222.6 \\
28 \\
\end{array}$ & 20.355.839 & 43.454 & $\begin{array}{r}20.399 .2 \\
91 \\
\end{array}$ \\
\hline$\%$ & $92,1 \%$ & $6,6 \%$ & $1,1 \%$ & $99,8 \%$ & $0,2 \%$ & $100 \%$ \\
\hline \multicolumn{7}{|l|}{$\begin{array}{l}\text { Employmen } \\
\text { t }\end{array}$} \\
\hline Number & 37.494 .458 & 26.704.352 & $\begin{array}{l}22.61 \\
2.906 \\
\end{array}$ & 86.814.717 & 43.787 .013 & $\begin{array}{r}130.601 . \\
730 \\
\end{array}$ \\
\hline$\%$ & $28,7 \%$ & $20,5 \%$ & $17,3 \%$ & $66,5 \%$ & $33,5 \%$ & $100 \%$ \\
\hline Value Added & at Factor & Costs & & & & \\
\hline $\begin{array}{l}\text { Million } \\
\text { Euros } \\
\end{array}$ & 1.242 .724 & 1.076 .388 & $\begin{array}{l}1.076 \\
0.270 \\
\end{array}$ & 3.395 .383 & 2.495 .926 & $\begin{array}{r}5.891 .30 \\
9 \\
\end{array}$ \\
\hline$\%$ & $21,1 \%$ & $18,3 \%$ & $18,3 \%$ & $57,6 \%$ & $42,4 \%$ & $100 \%$ \\
\hline
\end{tabular}

In terms of demography, European SMEs followed a different path from that of large companies. In 2009, the number of large firms dropped by almost 1.800 units to circa 42.400. Figure 1 shows the evolution of number of SMEs compared to the number of large firms.

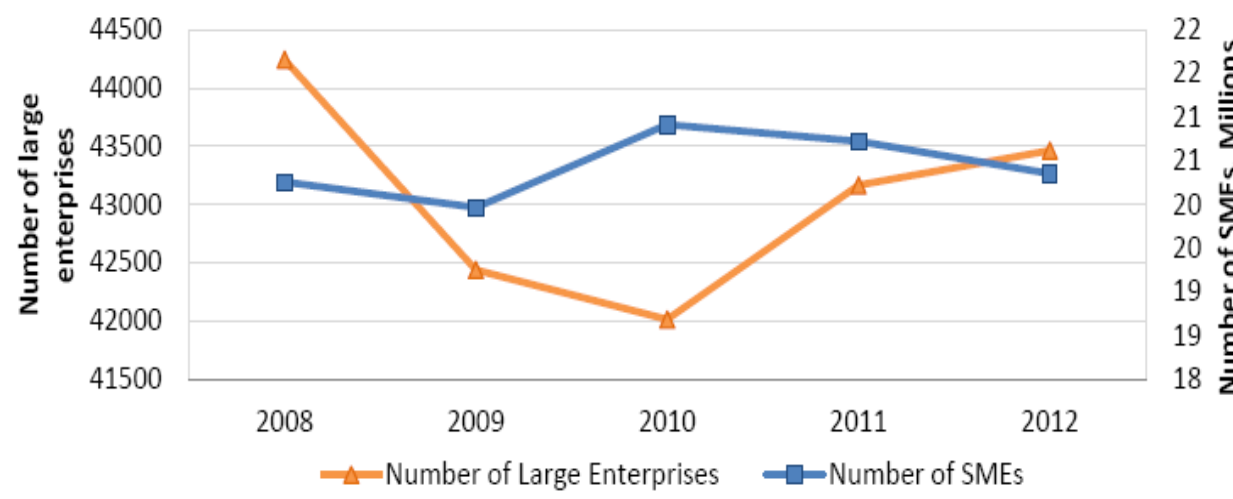

Figure 1 Number of Enterprises, EU-27, 2008-2012

Source: Dimitri Gagliardi et al. (2013), A RECOVERY ON THE HORIZON? Final Report, ANNUAL REPORT ON EUROPEAN SMEs 2012/2013, available at http://ec.europa.eu/enterprise/policies/sme/factsfigures-analysis/performance-review/files/supporting-documents/2013/annual-report-smes-2013_en.pdf

The number of SMEs began to grow again only in 2010 and in 2012 had not recovered to its 2009 level. The number of SMEs grew between 2009 and 2010 by almost 1 million firms, reaching 21 million, after a relatively small drop in 2009. From 2010 onwards, the total number of SMEs continued to fall, although at a slower rate. In 2012, the number of SMEs returned to the levels of 2008, but there were still 389.000 fewer SMEs than 2009. The small firm can easily adjust to even the most dynamic changes in the market. As they change they even improve their profit pictures.

SMEs accounted for $66.5 \%$ of all European jobs in 2012. In the sector such as real estate, accommodation and food services, professional, technical and research 
activities and construction, the SME share of total employment is over $80 \%$, whilst in other sectors such as electricity, gas, mining and quarrying and administrative and support services, the SME share is well below $50 \%$ of total employment.

The period 2009-2012 proved extremely challenging for employment in SMEs. Between 2008 and 2010, SME shod lost 1.5 million jobs. The majority of the job-loss was experienced by the micro-enterprises and small business (figure 2).

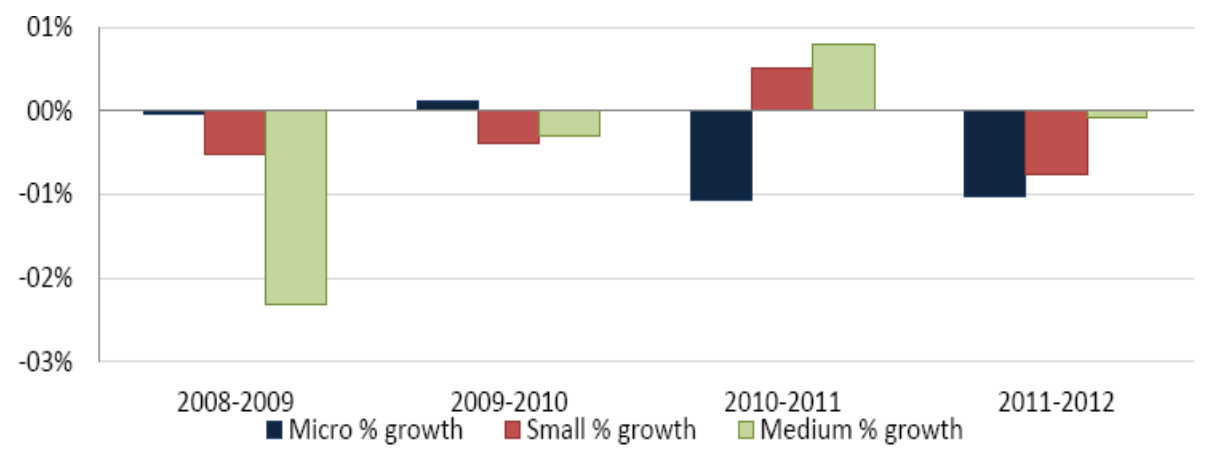

Figure 2 Employment in SMEs, EU -27, 2008-2012

Source: Dimitri Gagliardi et al. (2013), A RECOVERY ON THE HORIZON? Final Report, ANNUAL REPORT ON EUROPEAN SMEs 2012/2013, available at http://ec.europa.eu/enterprise/policies/sme/factsfigures-analysis/performance-review/files/supporting-documents/2013/annual-report-smes-2013_en.pdf

In 2012, SMEs lost 610.000 jobs, and the trend for each SME size band can be characterized as follows: micro-enterprises performed well between 2008 and 2010, but they showed a negative trend in 2011 and 2012; the trend for small enterprises was negative throughout the period; the major source of job losses in 2009 was in medium sized enterprises.

The overall contribution of SMEs to total EU-27 value added was more than $57 \%$ in 2012. This contribution differs markedly across sectors and by enterprise size. Figure 3 shows the contribution to gross valued added by size.

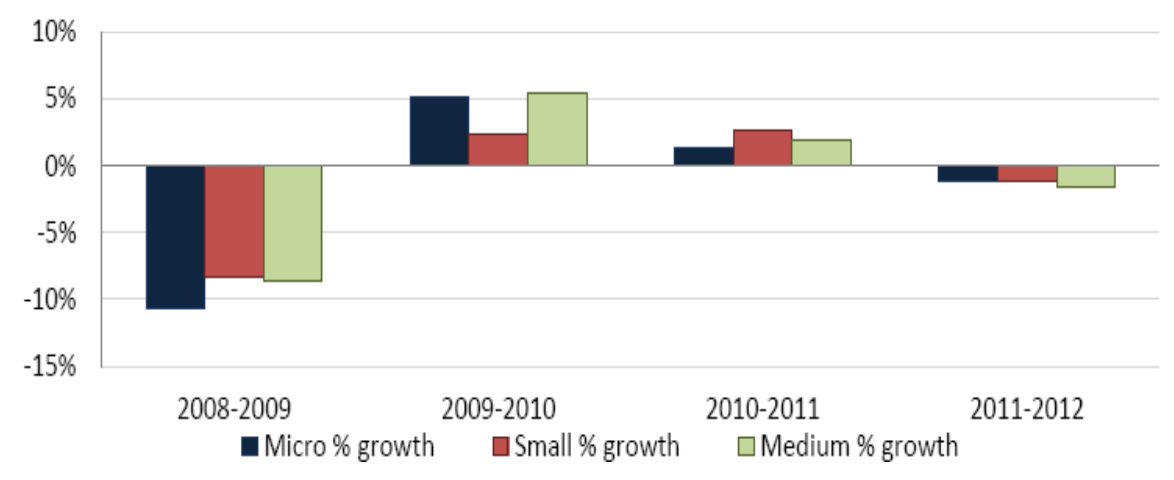

Figure 3 Gross value added in SMEs, EU-27, 2008-2012

Source: Dimitri Gagliardi et al. (2013), A RECOVERY ON THE HORIZON? Final Report, ANNUAL REPORT ON EUROPEAN SMEs 2012/2013, available at http://ec.europa.eu/enterprise/policies/sme/factsfigures-analysis/performance-review/files/supporting-documents/2013/annual-report-smes-2013_en.pdf

As we can see, micro-enterprises experienced the largest loss in 2009, in 2010 some of this loss was recouped, but in 2012 loss circa 14 billion in value added. Small and medium sized enterprises experienced the same dynamics. 


\section{Small Business in the 21st Century}

In modern economies economic activity by small firms is increasingly important for achieving economic growth. In the new context of the revolution of knowledge, of the passage from the economy dominated by the physical, tangible resources to the economy dominated by knowledge, the small and medium company becomes the main microeconomic pawn.

The globalization of the small enterprise will most likely be the most important development in international business as we begin the new millennium.

Globalization - the growing impetus to think and act on a worldwide scale - will continue to modify and mold the environment for small business over the next decade and beyond. The globalization of the company means that more and more new firms must export from their inception in order to be competitive. But they will profit from globalization only if it gives them access to new markets. To be competitive, SMEs may have to identify niche markets.

Small firms, including many start-ups, are identifying foreign markets and foreign sources of supply though the Internet as important parts of their strategies for growth and success. Because of the Internet, small businesses are also facing more foreign competition in the products and services they both provide and purchase. The competition from abroad puts strong pressure on small business in terms of efficiency, price, quality, cost control, marketing, expertise, customer satisfaction, and innovativeness. Small firms will prosper on the Internet or come to view it as another fixed cost necessary to maintain their present client base in an open question. This aspect of the small business environment will continue to evolve as small firms develop more creative and profitable uses for the Internet.

The next decade will see an increase in the connectivity between and among organizations and markets. Already, firms are electronically connected with their customers and vendors. Connectivity is fostering the development of new organizational relationships among entities. Alliances of small firms, self-employed individuals, and larger organizations connected by advanced computer and communications technologies are allowing geographically diverse organizations to interact and work creatively to produce goods and services all over the world. Increased flexibility and connectivity will both allow and require small business to be more responsive to their customers' particular needs. The development and design of new customized products will both give small firms an advantage and put pressure on them to produce customized products with greater speed than ever before. Small firms must diversify to a greater extent to maximize their ability to respond rapidly to new demands for products and services.

Changes in technology, markets, and values will encourage the evolution of new types of firms. Advances in computers, software, communications, and related technologies are already affecting the form and operational structure of both existing and emerging enterprises. Clusters of competencies and strategic alliances - with selfemployed individuals, small firms, and representatives of larger organizations often connected primarily by computer and communications networks and often working at great distances from each other - are expected to increase rapidly in number and importance over the next decade. These clusters can be created quickly, can work intensely on projects or a series or projects, and can just as quickly be disbanded. The self-employed individuals and small organizations included in these strategic alliances or clusters of competencies can, for a time, perform almost like traditional businesses. For small businesses and entrepreneurs to be successful over the next decade and beyond, an educated and trained work force must be available. Most small firms now identify labor shortages and the ability to obtain skilled labor at reasonable rates as their number one problem. Entrepreneurship education for students must focused on developing student's skills to start their own ventures, or a more enterprising attitude 
to different situations: developing more creative, innovative approaches to learning, school work and the school community; developing in students the self - esteem, confidence and positive attitudes necessary for consideration of entrepreneurship or self - employment as a viable career option; developing in students the attitudes, skills and behaviors to succeed in work - force entry and career progression; developing in students the positive attitudes, skills and behaviors needed for integration into the community and participation in its development.

\section{Conclusion}

Competition is the essential ingredient in the European business environment. It encourages businesses to make efficient use of resources. People will patronize efficient businesses rather than their inefficient rivals, so the efficient firms flourish and the inefficient ones go out of business.

The small business sector is regarded as a fundamental ingredient in the establishment of a modern, progressive and vibrant economy. There are a number of reasons why there is considerable interest in the creation, management, dynamics and contribution of small businesses:

- small firms help to diversify a nation's economic base and provide it with the opportunity of responding to a variety of market conditions;

- the creation of a new business venture provides an opportunity to transcend social inequality and the unemployment trap;

- the presence of small firms in an economy is an expression of healthy and necessary competition against the excesses of big business and monopoly power and exploitation;

- small firms are better able to adapt to changing and sometimes disruptive economic circumstances. Due to its flexibility, the sector is in an advantageous position to face challenges and changes. It is ideally poised to attract both technology and funds to generate rapid growth and sustained process of technology upgradation and quality improvement;

- small firms are the natural avenues for self-development and individual achievement, being the natural expression of entrepreneurship.

Across the EU policies are being developed at regional, national and transnational government level that see SMEs as the only positive way of creating employment and generating increased local growth for the community.

\section{References}

Gagliardi, Dimitri et al. (2013), A RECOVERY ON THE HORIZON? Final ReportANNUAL REPORT ON EUROPEAN SMEs 2012/2013, available at http://ec.europa.eu/enterprise/policies/sme/facts-figures-analysis/performancereview/files/supporting-documents/2013/annual-report-smes-2013_en.pdf

Marzocchi, C., Ramlogan, R., Gagliardi, D. (2013), Brief on SME FINANCING 2012/2013, Annual Report of European SMEs, Manchester Institute of Innovation Research MBS, the University of Manchester. UK available at http://ec.europa.eu/enterprise/policies/sme/facts-figures-analysis/performancereview/files/briefs/sme-financing-brief-2013-final_en.pdf

Nummela, N. (2011), Internatinal Growth of Small and Medium Enteprise, Routhdge, NY.

U.S. Small Business Administration (SBA) (2000), The Third Millennium: Small Business and Entrepreneurship in the 21th Century, available at www.sba.gov/advo/. 